\title{
Success of Crizotinib Combined with Whole-Brain Radiotherapy for Brain Metastases in a Patient with Anaplastic Lymphoma Kinase Rearrangement- Positive Non-Small-Cell Lung Cancer
}

\author{
Sachi Okawa ${ }^{a}$ Takuo Shibayama $^{a}$ Atsushi Shimonishi $^{a}$ Jun Nishimura ${ }^{a}$

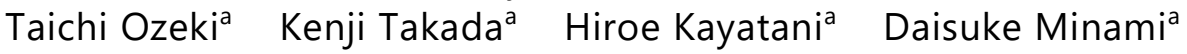 \\ Ken Sato ${ }^{a}$ Keiichi Fujiwara ${ }^{a}$ Toshiro Yonei ${ }^{a}$ Toshio Sato $^{a}$ \\ Manabu Suno ${ }^{b}$ \\ aDepartment of Respiratory Medicine, National Hospital Organization Okayama Medical \\ Center, Okayama, Japan; bepartment of Oncology, Pharmaceutical Care and Sciences, \\ Okayama University, Graduate School of Medicine, Dentistry and Pharmaceutical \\ Sciences, Okayama, Japan
}

\section{Keywords}

ALK rearrangement-positive NSCLC · Leptomeningeal carcinomatosis - Central nervous system failure · Crizotinib - Whole-brain radiotherapy · Blood-brain barrier permeability

\section{Abstract}

Although crizotinib shows marked antitumor activity in anaplastic lymphoma kinase (ALK) rearrangement-positive non-small-cell lung cancer (NSCLC) patients, all treated patients ultimately develop resistance to this drug. Isolated central nervous system failure without progression at extracranial sites is a common progression pattern in ALK rearrangement-positive NSCLC patients treated with crizotinib. Here, we report the success of crizotinib combined with 
whole-brain radiotherapy in an ALK rearrangement-positive NSCLC patient who developed leptomeningeal carcinomatosis and progression of multiple brain metastases. Additionally, we focused on the mechanism involved by examining the plasma and cerebrospinal fluid concentrations of crizotinib in the present case.

(C) 2018 The Author(s)

Published by S. Karger AG, Basel

\section{Introduction}

The echinoderm microtubule-associated protein-like 4-anaplastic lymphoma kinase (EML4-ALK) oncogene fusion is present in 4-5\% of non-small-cell lung cancers (NSCLCs) [1, 2]. Although crizotinib, an inhibitor of ALK tyrosine kinase, shows marked antitumor activity in ALK rearrangement-positive NSCLC patients, all treated patients ultimately develop resistance to this drug [3].

Isolated central nervous system (CNS) failure, defined as a CNS relapse without progression at extracranial sites, is a common progression pattern, besides systemic progression, in ALK rearrangement-positive NSCLC patients treated with crizotinib [4]. Extracranial tumors are considered to remain sensitive to crizotinib in patients who develop isolated CNS failure, and the continuation of crizotinib treatment beyond CNS progression has been reported in ALK rearrangement-positive NSCLC patients in whom CNS metastasis was well controlled with radiotherapy [5]. Here, we report the success of crizotinib combined with whole-brain radiotherapy (WBRT), which was performed owing to nonapproval of alectinib or ceritinib in Japan at the time, in an ALK rearrangement-positive NSCLC patient who developed leptomeningeal carcinomatosis (LM) and progression of multiple brain metastases.

\section{Case Report}

A 60-year-old male never-smoker presented to our hospital with back pain. Chest radiography revealed a mass lesion in the left lower lobe of the lung with left pleural effusion (Fig. 1a). Computed tomography of the chest/abdomen showed mediastinal lymph node swelling, pulmonary lymphangitic carcinomatosis, and right adrenal metastasis (Fig. 1b). Magnetic resonance imaging (MRI) revealed multiple, small, diffuse asymptomatic metastases of the brain (Fig. 1c), and bone scintigraphy showed multiple bone metastases. Transbronchial biopsy and cytological examination of the pleural effusion indicated adenocarcinoma of the lung, and he was finally diagnosed with adenocarcinoma of the lung (clinical stage IV, T4N2M1b) in May 2013.

Although chemotherapy with docetaxel and cisplatin was administered, the disease progressed. As a biopsy specimen revealed EML4-ALK rearrangement on both fluorescence in situ hybridization and immunohistochemistry during the first-line chemotherapy, he was administered crizotinib (250 mg twice daily) in July 2013. However, it was discontinued for a short time owing to grade 3 acute hepatic dysfunction and was later restarted at a dose of 200 mg twice daily. Two months after the initiation of crizotinib, the adrenal and brain metastases as well as the pulmonary mass, lymphangitic carcinomatosis, and pleural effusion regressed markedly. 


\section{Case Reports in Oncology}

Case Rep Oncol 2018;11:777-783

DOI: $10.1159 / 000492150$

(C) 2018 The Author(s). Published by S. Karger AG, Base www.karger.com/cro

Okawa et al.: Success of Crizotinib Combined with WBRT for Brain Metastases in a

Patient with Anaplastic Lymphoma Kinase Rearrangement-Positive NSCLC

Three months after regression, he complained of severe headache. MRI of the brain revealed progression of brain metastases (Fig. 2a), and cerebrospinal fluid (CSF) cytology from a lumbar puncture was positive for malignant cells. Isolated central nervous system failure was observed without progression at extracranial sites. He received WBRT (30 Gy) and continued to receive crizotinib, but the dose was increased to $250 \mathrm{mg}$ twice daily after the initiation of WBRT. Three weeks later, the metastatic brain tumors regressed (Fig. 2b), and CSF cytology was negative for malignant cells (Fig. 2). His severe headache was well controlled, and, therefore, he was followed up at the outpatient clinic.

His plasma and CSF were examined thrice at 1-week intervals to evaluate the effect of crizotinib combined with WBRT. Plasma was collected at around $5 \mathrm{~h}$ after crizotinib administration, according to a previous report [6]. The concentration of crizotinib was measured using a validated high-performance liquid chromatography with tandem mass spectrometry [7]. The crizotinib concentrations in the plasma and CSF were measured at 4 time points (1 before and 3 after the initiation of WBRT at 1-week intervals). The plasma concentrations of crizotinib were $136.6 \mathrm{ng} / \mathrm{mL}(0.31 \mu \mathrm{mol} / \mathrm{L})$ before WBRT, and $133.4 \mathrm{ng} / \mathrm{mL}(0.30 \mu \mathrm{mol} / \mathrm{L})$, $176.7 \mathrm{ng} / \mathrm{mL}(0.40 \mu \mathrm{mol} / \mathrm{L})$, and $286.1 \mathrm{ng} / \mathrm{mL}(0.64 \mu \mathrm{mol} / \mathrm{L})$ after the initiation of WBRT. Additionally, the CSF concentrations of crizotinib were lower than the quantification limit before WBRT and at 1 time point after the initiation of WBRT and were $6.2 \mathrm{ng} / \mathrm{mL}(0.014 \mu \mathrm{mol} / \mathrm{L})$ and $6.3 \mathrm{ng} / \mathrm{mL}(0.014 \mu \mathrm{mol} / \mathrm{L})$ at the remaining 2 time points, with a CSF-to-plasma ratio of 0.035 and 0.022 at the last 2 time points (Table 1 ).

Isolated CNS failure was noted 6 months later. Although he received intrathecal methotrexate and cytarabine, followed by intravenous pemetrexed, the disease continued to progress, and 4 months after the second CNS failure, he died.

\section{Discussion}

We reported the success of crizotinib combined with WBRT in an ALK rearrangementpositive NSCLC patient who developed LM and progression of multiple brain metastases. Isolated CNS failure is a common progression pattern in ALK rearrangement-positive NSCLC patients treated with crizotinib [4]. Costa et al. [6] reported that the most likely reason for isolated CNS failure is incomplete penetration of the blood-brain barrier (BBB) by crizotinib. In their report, after completing 2 weeks of WBRT, crizotinib was restarted at a dose of $250 \mathrm{mg}$ twice daily, and 2 weeks later, the plasma and CSF concentrations of crizotinib were found to be $237 \mathrm{ng} / \mathrm{mL}(0.53 \mu \mathrm{mol} / \mathrm{L})$ and $0.616 \mathrm{ng} / \mathrm{mL}(0.0014 \mu \mathrm{mol} / \mathrm{L})$, respectively, with a CSF-toplasma ratio of 0.0026 . The plasma concentration of crizotinib in our case was similar to the one in this previous report; however, the CSF-to-plasma ratio of 0.022 in our case was almost 10 times higher than that in this previous report. Additionally, in our case, crizotinib was effective not only for extracranial systemic control but also for LM, which is contrary to the finding in this previous case report.

A previous study showed that fractionated brain irradiation increased the BBB permeability in a murine model, allowing transport across the BBB [8]. In our case, although the CSF concentration of crizotinib was lower than the quantification limit at 1 week after initiating WBRT, the concentration increased to 6.2 and $6.3 \mathrm{ng} / \mathrm{mL}$ at 2 and 3 weeks, respectively, after initiating WBRT, indicating that the transport of crizotinib across the BBB increased owing to 
destruction of the BBB by WBRT. Therefore, in our case, crizotinib continuation was effective for $\mathrm{LM}$ because the destruction of the BBB with WBRT resulted in a high concentration of crizotinib in the CSF.

Although treatment approaches for LM are present, such as intrathecal or systemic chemotherapy and whole-brain irradiation, a standard treatment approach has not been established. Johung et al. [9] reported that patients with brain metastases from ALK-rearranged NSCLC treated with radiotherapy (stereotactic radiosurgery and/or WBRT) and tyrosine kinase inhibitors have prolonged survival. On the other hand, there have been conflicting reports on the use of crizotinib for CNS metastasis [10-12], and the mechanism involved has not yet been fully understood. Therefore, the selection of a treatment approach for LM in ALK rearrangement-positive NCLSC patients with CNS metastasis is difficult.

Since the second-generation ALK tyrosine kinase inhibitor alectinib was approved in 2014, high-dose alectinib has shown to be active against CNS failure after crizotinib treatment for NSCLCs [13]. According to recent findings, alectinib rather than crizotinib should be considered for ALK rearrangement-positive NCLSC patients with CNS metastasis. On the other hand, rearrangements of the c-ros oncogene 1, receptor tyrosine kinase (ROS1) gene, which has shown to be associated with favorable antitumor activity to crizotinib, are reported in 1$2 \%$ of lung adenocarcinomas. Zhang et al. [14] reported success in a case receiving crizotinib combined with palliative operation and radiation therapy for the treatment of ROS1-positive lung adenocarcinoma with symptomatic brain metastases. If crizotinib concentrations in the CSF can be monitored as in the present case, crizotinib combined with WBRT could be an optional strategy for ROS1-positive NCLSC patients with CNS metastasis. Although there are quite a few cases of ROS1-positive lung cancer, it is unclear why crizotinib can be effective against CNS metastasis. Therefore, further investigation is required to reveal the mechanisms involved.

In conclusion, we presented the successful treatment with crizotinib combined with WBRT in an ALK rearrangement-positive NSCLC patient who developed LM and progression of multiple brain metastases.

\section{Acknowledgment}

The authors thank the patient for consenting to plasma and CSF sampling for research purposes as well as providing written informed consent for the publication of this case report.

\section{Statement of Ethics}

All procedures performed in the study involving human participants were in accordance with the ethical standards of the institutional and/or national research committee and with the 1964 Helsinki Declaration and its later amendments or comparable ethical standards. 


\section{Disclosure Statement}

\section{All authors declare that they have no conflicts of interest.}

\section{References}

1 Soda M, Choi YL, Enomoto M, Takada S, Yamashita Y, Ishikawa S et al. Identification of the transforming EML4-ALK fusion gene in non-small-cell lung cancer. Nature. 2007 Aug;448(7153):561-6.

2 Takeuchi K, Choi YL, Soda M, Inamura K, Togashi Y, Hatano S et al. Multiplex reverse transcription-PCR screening for EML4-ALK fusion transcripts. Clin Cancer Res. 2008 Oct;14(20):6618-24.

3 Kwak EL, Bang YJ, Camidge DR, Shaw AT, Solomon B, Maki RG et al. Anaplastic lymphoma kinase inhibition in non-small-cell lung cancer. N Engl J Med. 2010 Oct;363(18):1693-703.

4 Camidge DR, Bang YJ, Kwak EL, Iafrate AJ, Varella-Garcia M, Fox SB et al. Activity and safety of crizotinib in patients with ALK-positive non-small-cell lung cancer: updated results from a phase 1 study. Lancet Oncol. 2012 Oct;13(10):1011-9.

5 Takeda M, Okamoto I, Nakagawa K. Clinical impact of continued crizotinib administration after isolated central nervous system progression in patients with lung cancer positive for ALK rearrangement. J Thorac Oncol. 2013 May;8(5):654-7.

6 Costa DB, Kobayashi S, Pandya SS, Yeo WL, Shen Z, Tan W et al. CSF concentration of the anaplastic lymphoma kinase inhibitor crizotinib. J Clin Oncol. 2011 May;29(15):e443-5.

7 Yamazaki S, Skaptason J, Romero D, Vekich S, Jones HM, Tan W et al. Prediction of oral pharmacokinetics of cMet kinase inhibitors in humans: physiologically based pharmacokinetic model versus traditional onecompartment model. Drug Metab Dispos. 2011 Mar;39(3):383-93.

8 Yuan H, Gaber MW, Boyd K, Wilson CM, Kiani MF, Merchant TE. Effects of fractionated radiation on the brain vasculature in a murine model: blood-brain barrier permeability, astrocyte proliferation, and ultrastructural changes. Int J Radiat Oncol Biol Phys. 2006 Nov;66(3):860-6.

9 Johung KL, Yeh N, Desai NB, Williams TM, Lautenschlaeger T, Arvold ND et al. Extended Survival and Prognostic Factors for Patients With ALK-Rearranged Non-Small-Cell Lung Cancer and Brain Metastasis. J Clin Oncol. 2016 Jan;34(2):123-9.

10 Isozaki H, Yasugi M, Takigawa N, Hotta K, Ichihara E, Taniguchi A et al. A new human lung adenocarcinoma cell line harboring the EML4-ALK fusion gene. Jpn J Clin Oncol. 2014 Oct;44(10):963-8.

11 Kinoshita Y, Koga Y, Sakamoto A, Hidaka K. Long-lasting response to crizotinib in brain metastases due to EML4-ALK-rearranged non-small-cell lung cancer. BMJ Case Rep. 2013 Sep;2013:bcr-2013-200867.

12 Maillet D, Martel-Lafay I, Arpin D, Pérol M. Ineffectiveness of crizotinib on brain metastases in two cases of lung adenocarcinoma with EML4-ALK rearrangement. J Thorac Oncol. 2013 Apr;8(4):e30-1.

13 Gadgeel SM, Gandhi L, Riely GJ, Chiappori AA, West HL, Azada MC et al. Safety and activity of alectinib against systemic disease and brain metastases in patients with crizotinib-resistant ALK-rearranged non-small-cell lung cancer (AF-002JG): results from the dose-finding portion of a phase 1/2 study. Lancet Oncol. 2014 Sep;15(10):1119-28.

14 Zhang M, Nie L, Zhang J. Crizotinib Treatment Combined with Resection and Whole-brain Radiation Therapy in a ROS1 Rearranged Lung Adenocarcinoma with Brain Metastasis: Case Report and Literature Review. Zhongguo Fei Ai Za Zhi. 2016 Aug;19(8):525-9. Chinese. 


\section{Case Reports in Oncology}
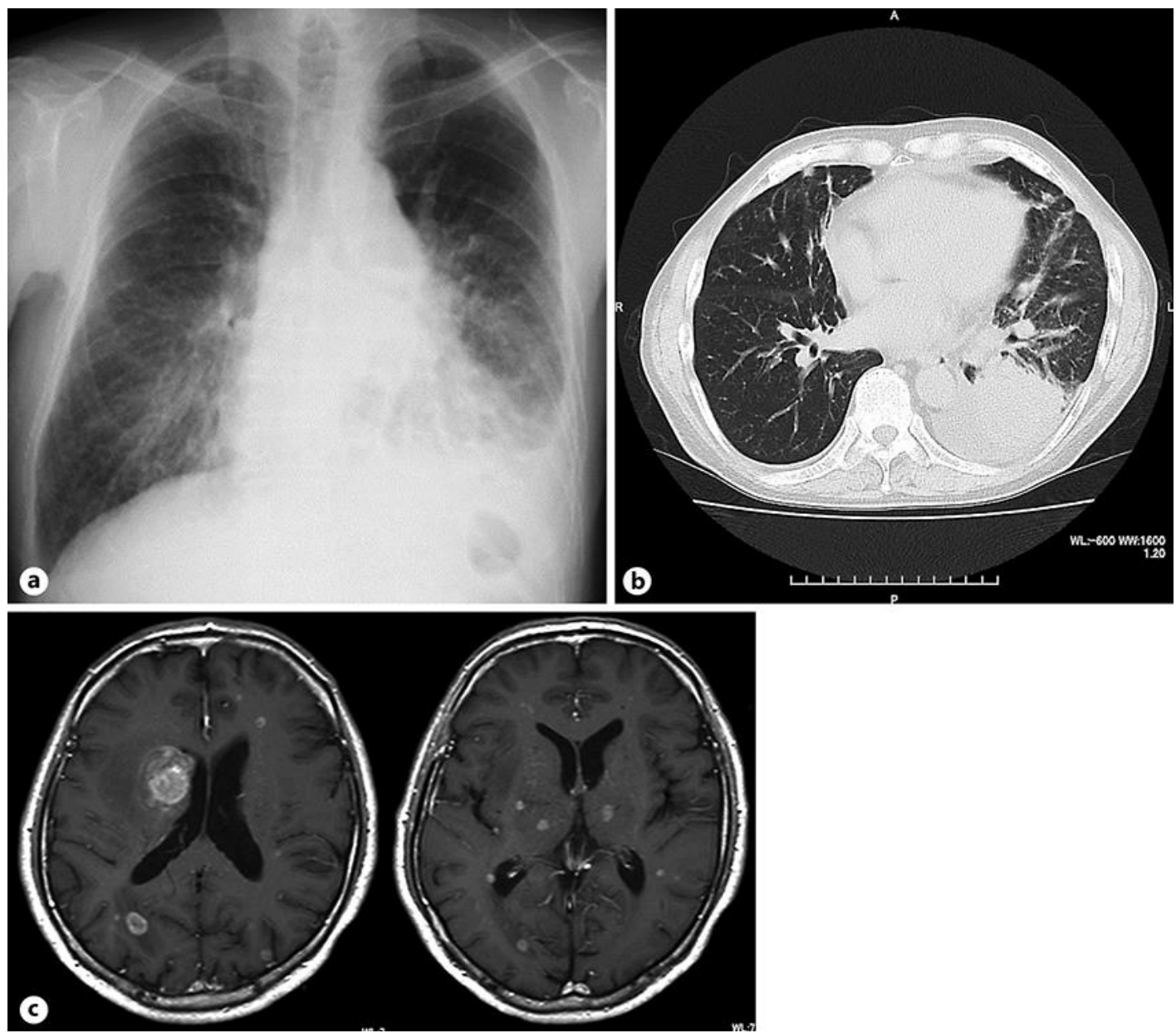

Fig. 1. Radiographic findings on admission. Chest radiography (a), chest computed tomography (b), and contrast-enhanced brain magnetic resonance imaging (c) show a mass lesion in the left lower lobe of the lung with left pleural effusion, pulmonary lymphangitic carcinomatosis, and multiple brain metastases. 


\section{Case Reports in Oncology}

WBRT (30 Gy)

CSF cytology result
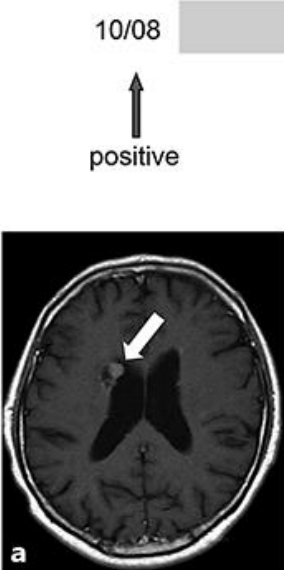

\section{$10 / 18$}

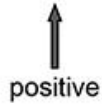

positive
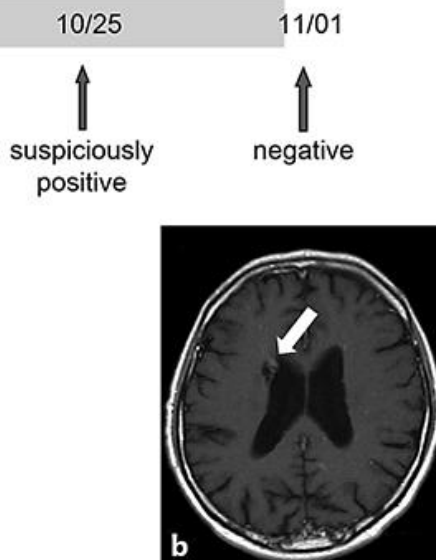

Fig. 2. Treatment schedule, cerebrospinal fluid (CSF) cytology, and magnetic resonance (MR) imaging findings. CFS cytology was negative for malignant cells at 3 weeks after crizotinib (250 mg twice daily) combined with whole-brain radiotherapy (WBRT; $30 \mathrm{~Gy}$ ). a Brain MR image obtained before treatment shows a single brain metastatic lesion. b Brain MR image obtained 3 weeks after the initiation of WBRT shows a decrease in size of the metastatic lesion.

Table 1. Crizotinib concentrations in the plasma and cerebrospinal fluid

\begin{tabular}{llllr}
\hline & \multicolumn{4}{l}{ Date of collection } \\
\cline { 2 - 5 } & October 8 & October 18 & October 25 & November 1 \\
\hline Plasma concentration, $\mathrm{ng} / \mathrm{mL}$ & 136.6 & 133.4 & 176.7 & 286.1 \\
Cerebrospinal fluid concentration, $\mathrm{ng} / \mathrm{mL}$ & $\mathrm{ND}$ & $\mathrm{ND}$ & 6.2 & 6.3 \\
\hline
\end{tabular}

ND, not detected because the concentration was lower than the quantification limit. 